\title{
Measurement of temperature in a margin of Ice Stream B, Antarctica: implications for margin migration and lateral drag
}

\author{
W. D. Harrison, K. A. Eqhelmeyer, C. F. Larsen \\ Geophysical Institute, University of Alaska-Fairbanks, Fairbanks, Alaska 99775-7320, U.S.A.
}

\begin{abstract}
Ice temperature was measured in and around the chaotically crevassed south margin of Ice Stream B, Antarctica, from 1992 to 1994. The temperatures at $30 \mathrm{~m}$ depth in the chaotic zone are about $12 \mathrm{~K}$ lower than in the adjacent uncrevassed ice, due to the ponding of cold winter air. At depths greater than $150 \mathrm{~m}$, there is clear evidence of internal heating of the ice due to the large shear deformation rate in the marginal zone. Analysis of the depth of cooling below the crevasses and of the internal heating gives two pieces of information. First, over the last half century the lateral shear stress averaged $2.0 \times 10^{5} \mathrm{~Pa}$ in the top third of the margin and, second, the margin moved outward at an average rate of $7.3 \mathrm{~m} \mathrm{a}^{-1}$. These values do not involve any assumptions about the flow law of ice. The uncertainties are roughly $20 \%$. The value of lateral shear stress indicates that the most of the drag on the ice stream is along its sides.
\end{abstract}

\section{INTRODUCTION}

The large ice streams of the Siple Coast, Antarctica (Fig. 1), are thought to play a key role in the dynamics and balance of the West Antarctic ice sheet, which is grounded below sea level and therefore may be subject to mechanical instability (e.g. Hughes, 1975; Bentley, 1987; Alley and Whillans, 1991). These ice streams are unusual in several ways and two of their peculiarities are addressed in this paper. First, they can undergo large changes on time-scales of a century or perhaps much less, despite their great lengths of hundreds of kilometers. Secondly, they have such a low basal shear stress that their motion appears to be controlled largely by forces acting on their sides, even though they are wide (tens of kilometers) and thin $(1 \mathrm{~km})$.

The south margin of Ice Stream B2 has been studied extensively because nearby camps and skiways have made it accessible. The ice stream is about $31 \mathrm{~km}$ wide and $1 \mathrm{~km}$ thick in this region, and has the well-defined, heavily crevassed margins typical of the edges of most active ice streams (Fig. 2). The margin consists of three reasonably well-defined areas (Fig. 3): a zone of arcuate crevasses, a heavily crevassed "chaotic" zone called the "Dragon" and a zone of crevasses which trend upstream (Vornberger and Whillans, 1990; Echelmeyer and others, 1994). Measurements of surface velocity and shear strain rate across the Dragon (Bindschadler and others, 1987; Jackson, 1991; Whillans and others, 1993; Echelmeyer and others, 1994; Whillans and Van der Veen, 1997) and a laboratory study of ice cores retrieved from depth there (Jackson and Kamb, 1997) suggest that a large part of the downslope component of the weight of the ice stream is supported by the shear stress on an approximately vertical surface parallel to the edge of the ice stream. We call this the lateral shear stress. This interpre- tation is consistent with the weakness of the till found to underlie at least part of the ice stream (Kamb, 1991). Another interesting characteristic of the area is that much of the presently almost stagnant area to the south of the margin (the Unicorn in Figure l) is underlain by buried crevasses and was probably part of the ice stream a century or so ago (Clarke and Bentley, 1995). Such rapid changes appear to be common in the Siple Coast area (e.g. Bindschadler and Vornberger, 1990, 1998; Jacobel and others, 1996). There is also evidence that the margin is migrating outward at present (Hamilton and others, 1998) and that the ice stream is migrating upstream into previously relatively stagnant areas (Alley and Whillans, 1991). A theoretical discussion of the thermomechanical stability of icestream margins has been given recently by Jacobson and Raymond (1998).

The work described here was designed to provide new information about both the lateral shear stress and the migration of the edge of the ice stream. Both of these have a connection with the internal heating due to ice deformation, which we knew from our previous work could be significant in the Dragon (Echelmeyer and others, 1994). It was therefore apparent that the measurement of temperature might yield interesting information, if the field difficulties due to heavy crevassing could be overcome. Such measurements were carried out during the field seasons of 199293 and 1993-94 at the sites shown in Figures 1 and 3. We expected that the data would provide a constraint between the shear stress and the rate of migration of the edge of the ice stream but not the individual quantities. It turned out that a fortunate but unexpected circumstance, the cooling of the shallow ice by extensive crevassing, provided an extra piece of information that permitted both shear stress and migration rate to be determined. 

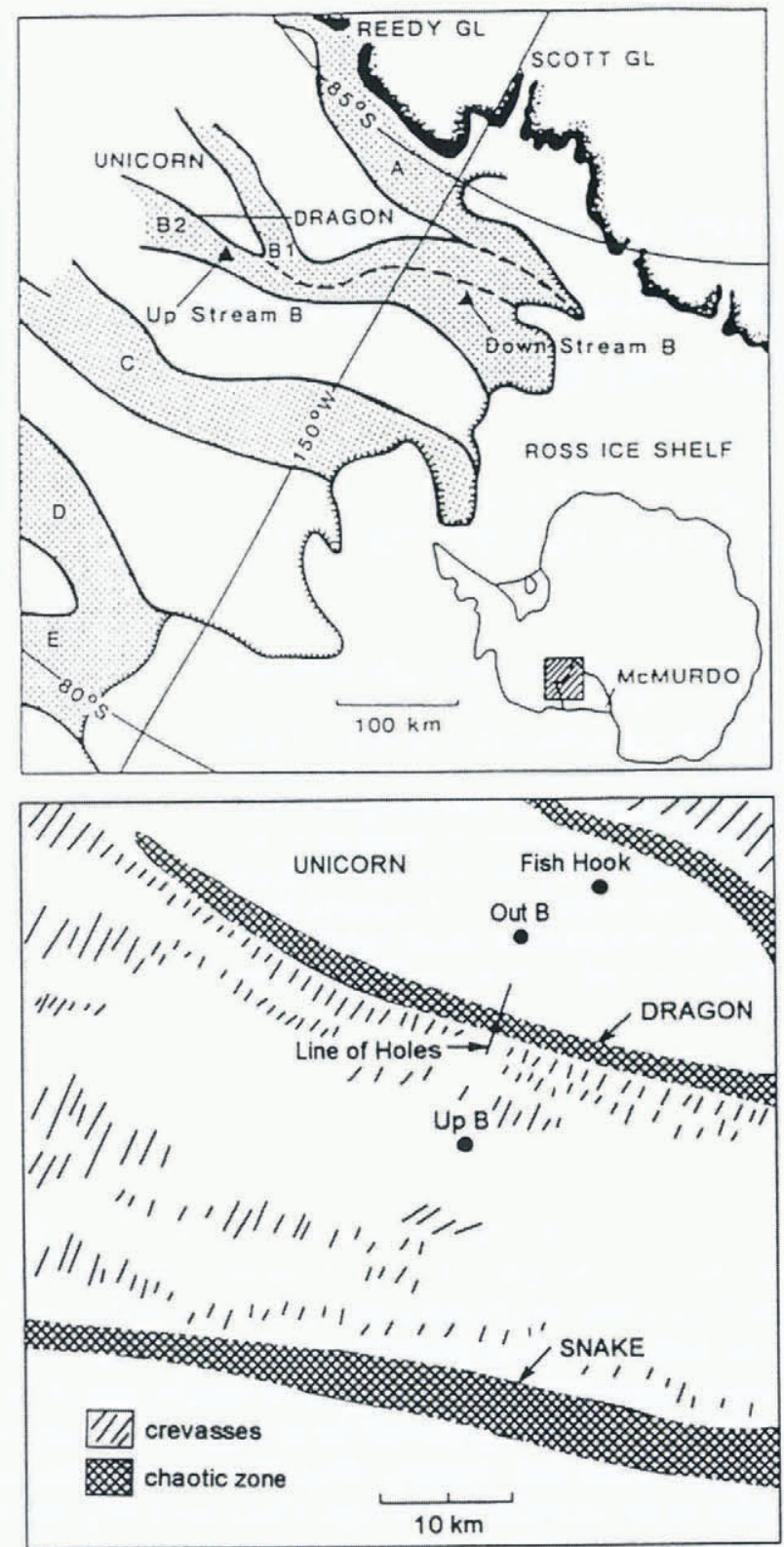

Fig. 1. Location map. The boreholes were drilled at Fish Hook, near OutB camp, and along the line indicated. The coordinates of OutB camp are $83^{\circ} 37^{\prime} 01^{\prime \prime} \mathrm{S}, 138^{\circ} 03^{\prime} 30^{\prime \prime} \mathrm{W}$. Modified from Shabtaie and Bentley (1986) and Vornberger and Whillans (1986).

\section{MEASUREMENTS AND RESULTS}

\section{A. Temperature}

Temperature measurements were made with thermistors frozen into borcholes drilled with hot water from the California Institute of Technology drill rig. Because of the heavy crevassing within the Dragon, the drill rig (which weighs about $10^{4} \mathrm{~kg}$ exclusive of fuel) was stationed outside it and the hot water from the rig was pumped to the boreholes through hose. The hose was dragged into place and partially supported with bamboo poles to limit its melting into the surface. A minimum of equipment (about $700 \mathrm{~kg}$ ) was manhauled and carried to the borehole sites: a drill tip and drilling hose, a hose-handling capstan, a heater to boost the water temperature, a small generator and fuel.

We accessed the Dragon from the ice stream in 1992-93 and from the Unicorn in 1993-94 (Fig. 1). Finding a route for

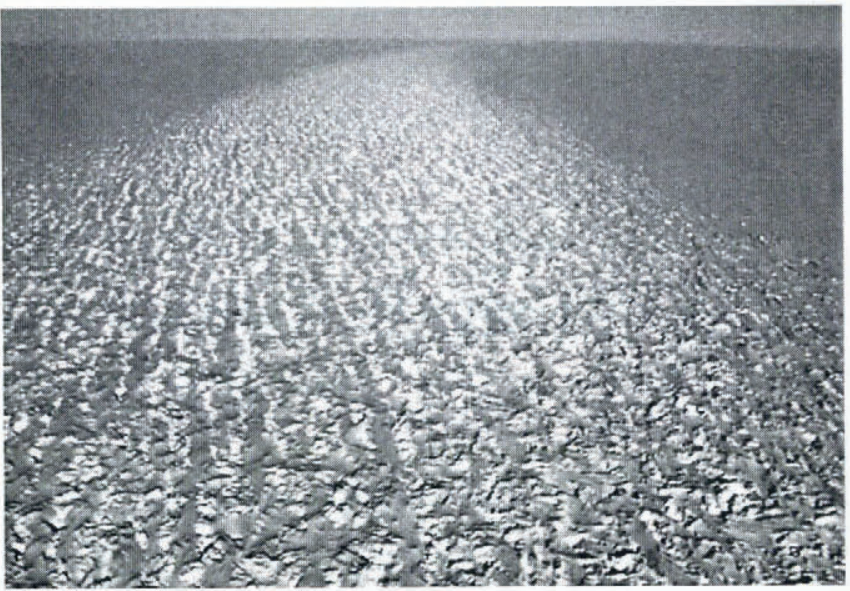

Fig. 2. An oblique view of the Dragon, looking upstream near the study area. The Unicorn is on the right.
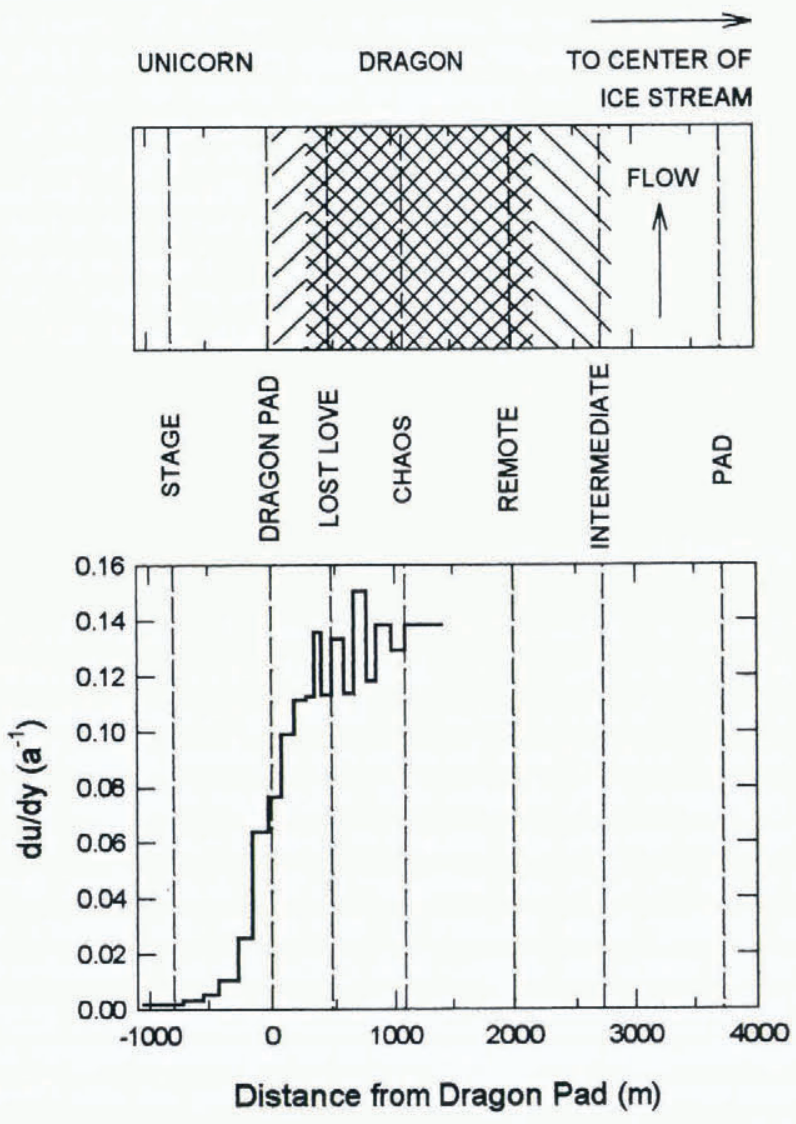

Fig. 3. Locations of boreholes in and near the Dragon, and the transverse derivative of the longitudinal velocity $\mathrm{d} u / \mathrm{d} y$ measured over the interval fanuary 1994- January 1995, shown with respect to the structure of the Dragon. The boundaries of the chaotic zone are somewhat diffuse, as seen in Figure 2. On the Unicorn side, the transition from arcuate to chaotic crevasses takes place between roughly 100 and $300 \mathrm{~m}$ on the distance scale shown.

the rig from the skiways at Upstream B and Out B camps (Fig. 1) to the Dragon was a major problem, especially from the ice-stream side. Although the drill rig never entered the Dragon, it was brought piecewise as close as safety permitted, through kilometers of open and hidden crevasses. Routes were found by exhaustive hand drilling and probing. Sometimes crevasses that were difficult to trace on the surface were entered and mapped from below. Transport of equipment, fuel and personnel was by snowmobile outside the Dragon, and by skis and handhauled sleds within it. Despite many trips, no crevasse falls occurred while trans- 
porting the drill rig or personnel to and from the Dragon, and only one or two minor ones within it. The dangers were more severe where the route was not so well studied. For example, a massive snow and ice bridge under a ski route used for surveying near the inner edge of the Dragon collapsed between visits; the dimensions of the collapse were comparable to the length of a climbing rope.

The thermistors were factory-calibrated at several temperatures and checked in our laboratory at $0^{\circ} \mathrm{C}$. After field installation they were measured daily with data loggers, the performance of which was checked daily using precision resistors as standards. The accuracy was a few hundredths of a kelvin. The data were recovered in January of 1993 and 1994. Equilibrium temperatures were estimated by constructing plots of temperature vs reciprocal time, which for an instantaneous line source are linear (e.g. Humphrey and Echelmeyer, 1990, p. 296) and in practice were usually easily extrapolated to infinite time. In most cases, equilibrium temperatures could be estimated to within $0.05 \mathrm{~K}$ but, at sites such as Chaos and Remote (Fig. 1), where there was limited time for data collection, the accuracy was closer to $0.1 \mathrm{~K}$. In a few cases, equilibrium temperatures could not be estimated, particularly in the Dragon at about $30 \mathrm{~m}$ depth, where there was a massive disturbance from the freezing of thousands of liters of return water flow from the drilling, which did not return to the surface but apparently ponded in the bottoms of crevasses.

The equilibrium temperatures are summarized in Figures 4 and 5 (see also Harrison and Echelmeyer, 1994) and the borehole locations are shown in Figures 1 and 3. The sites Remote, Intermediate and Pad were drilled in 199293 and the others in 1993-94, except for Up B, the data for which were taken from Engelhardt and Kamb (1994). In addition to these data, summer temperatures in crevasses were obtained by suspended thermistor strings and by direct measurement with thermometers (Fig. 6). Crevasse temperatures tended to vary erratically with time, possibly because of air convection.

\section{B. Other measurements}

The positions of the temperature-measurement sites and the surface velocities were determined by optical surveying. The

\section{Temperature $\left({ }^{\circ} \mathrm{C}\right)$}

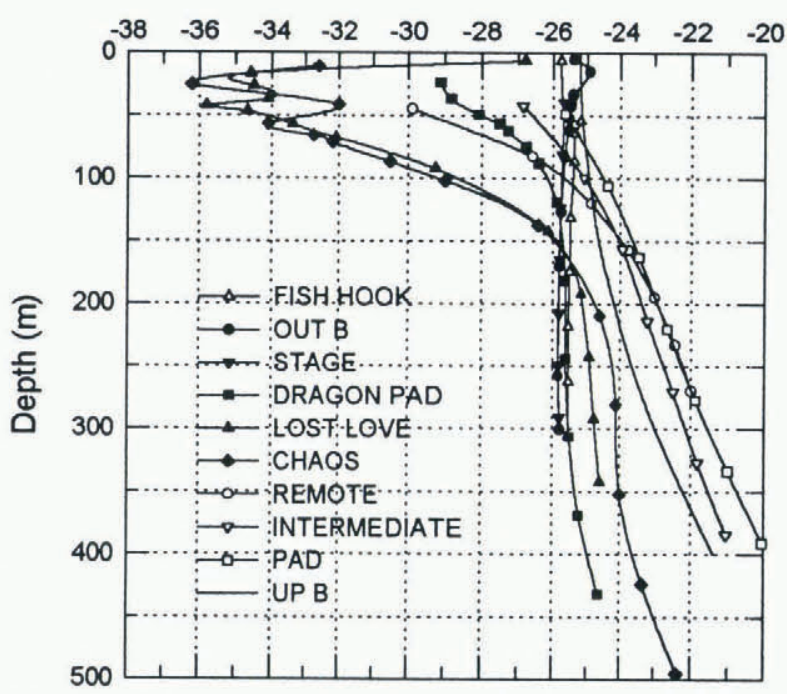

Fig. 4. Measured temperatures at the locations indicated in Figures 1 and 3 .

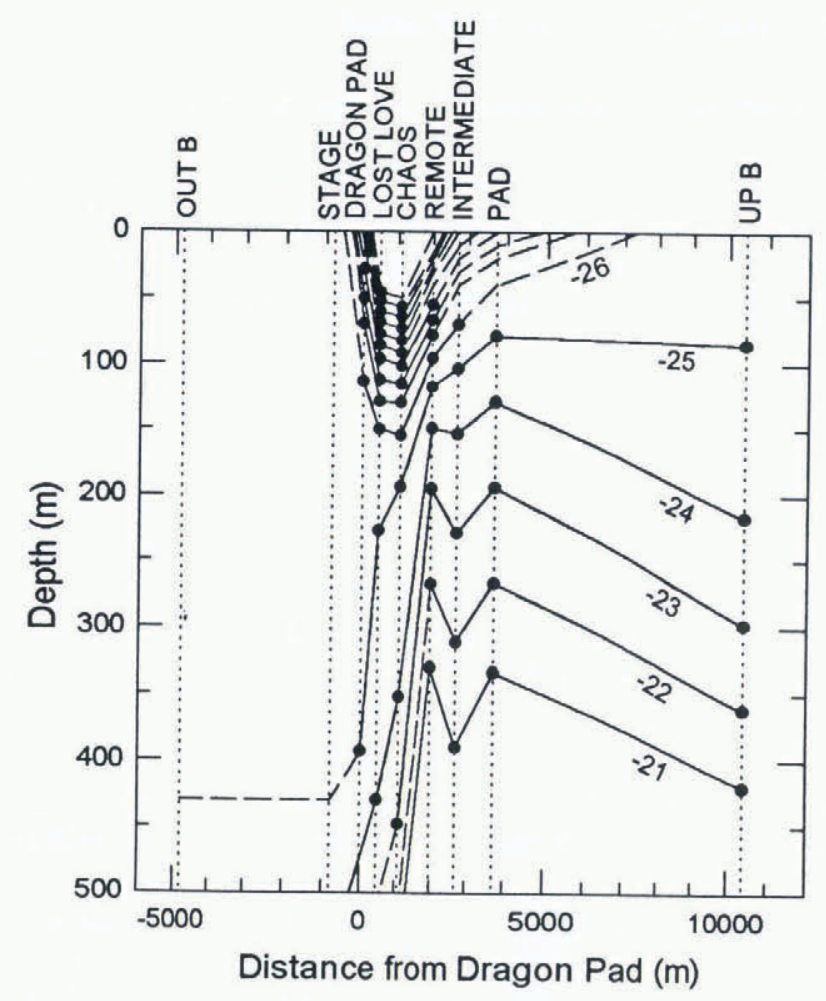

Fig. 5. Vertical cross-section of temperature between $U_{p} B$ and OutB, using data from Figure 4. The contours are labelled with temperature $\left({ }^{\circ} \mathrm{C}\right)$.

latter were measured along three profiles crossing the margin perpendicular to its edge. One line contained the temperature-measurement sites. The lateral derivative of the longitudinal velocity component along this line, which is approximately twice the lateral shear strain rate, is shown in Figure 3. The velocity with respect to bedrock of a marker just outside the ice stream (I21 near Dragon Pad) was measured by geodetic GPS methods and found to have a component inward to the ice stream (cf. Whillans and Van der Veen, 1993). Similar methods were used to measure surface slope. We also made monopulse radar measurements of ice thickness along the velocity lines; the results agreed with the drilling data at Dragon Pad (personal communication from H. Engelhardt, 1994). Those data needed for the analysis of the temperature data are summarized in Table 1.

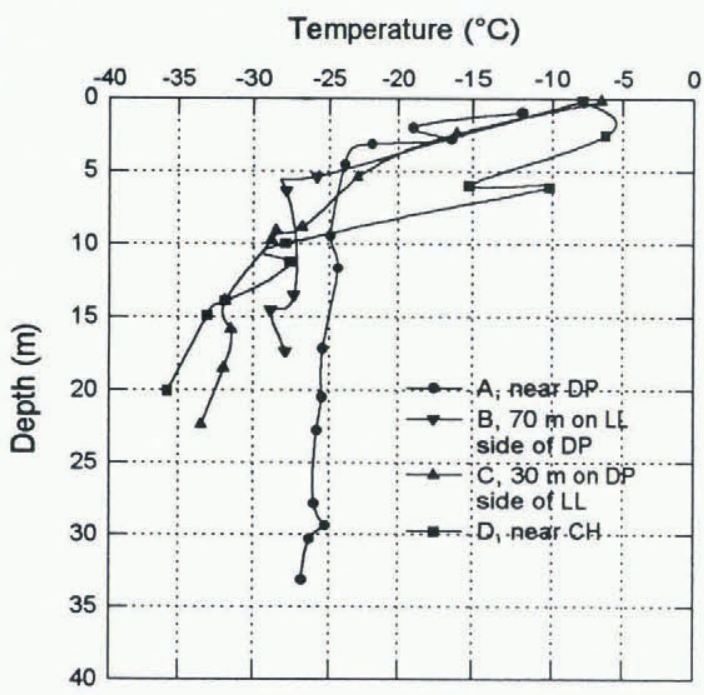

Fig. 6. Crevasse temperatures measured at four sites, as described in the legend. DP, LL and CH stand for Dragon Pad, Lost Love and Chaos, respectively. 


\section{DISCUSSION OF THE DATA}

\section{A. Crevasses and crevasse temperatures}

Our experience in sub-surface exploration in connection with route finding and temperature measurement indicates that the crevasses tend to be about $30 \mathrm{~m}$ deep or perhaps slightly more outside the Dragon. They might extend deeper but they are partially filled with collapsed snow bridges and sometimes large folded sheets of ice spalled from the crevasse walls, which in the course of their slow collapse often resemble giant pieces of ribbon candy. Where the crevassing is heavy, it seems completely chaotic on the ground, although patterns can be seen from the air (Fig. 2). The chaos usually prevents a person from reaching $30 \mathrm{~m}$ depth, or even from dangling a thermistor cable to $30 \mathrm{~m}$. Because of this, the crevasses at B, C and D are certainly deeper than the temperature data in Figure 6 would imply. That the depths in the Dragon are roughly $30 \mathrm{~m}$ is indicated by the disequilibrium effects in the temperatures near this depth at Lost Love and Chaos, which were caused by drilling water as noted above.

Crevasse A in Figure 6 was a deep arcuate crevasse near Dragon Pad. It was completely covered with a snow bridge and could only be entered after digging an access hole. In the analysis of the next section, the temperature at the bottoms of the crevasses (near $30 \mathrm{~m}$ depth) between Dragon Pad and Lost Love is important. Although the data from crevasse sites B, C and D do not extend this deep, they suggest by extrapolation a complex pattern of gradually decreasing temperature at $30 \mathrm{~m}$ as the Dragon is approached and entered from the Unicorn side.

\section{B. Temperatures at shallow depths}

The most striking feature of the data is the low temperatures at shallow $(<150 \mathrm{~m})$ depths within the margin. This is most apparent at Lost Love and Chaos but it is also seen at Dragon Pad, Remote and Intermediate (Fig. 4). (At Lost Love and Chaos the temperatures above about $30 \mathrm{~m}$ depth should be disregarded because they are complicated by the drilling and perhaps by other effects.) The low temperatures are associated with crevassing and are most pronounced where crevassing is intense and the crevasses are open at the surface. The obvious explanation is that cold winter air is ponded in the crevasses. Upward extrapolation at Lost Love and Chaos indicates that the mean annual temperature near the bottom of the crevasses at a depth of $30 \mathrm{~m}$ is about $-37.0^{\circ} \mathrm{C}$ at both sites. This is to be compared with $-25^{\circ}$ or $-26^{\circ} \mathrm{C}$ at $30 \mathrm{~m}$ depth that is typical of uncrevassed areas such as Fish Hook, Out B and Stage, and with the average mid-winter air temperatures of $-35^{\circ}$ to $-40^{\circ} \mathrm{C}$ (Harrison and Echlemeyer, 1994, fig. 11). The cooling in heavily crevassed areas is thus substantial, 11 or $12 \mathrm{~K}$.

\section{Temperatures at intermediate depths}

One can also distinguish characteristic types of temperature behavior at intermediate $(>150 \mathrm{~m})$ depths. Outside the ice stream on the Unicorn (Fish Hook, Out B and Stage), there is little variation of temperature down to the depths measured (roughly one-third of the ice thickness), except for a slight cooling with increasing depth. On the inner edge of the Dragon (Remote, Intermediate and Pad), there is a pronounced increase of temperature with depth. Within the
Table 1. Results from surface measurements

Distance $(\mathrm{m})$

Dragon Pad to Lost Love

Lost Love to Chaos

469

621

Average surface shear strain rate $\dot{e}_{x y}\left(\mathrm{a}^{-1}\right)$

Dragon Pad to Lost Love

0.054

Inward component of ice velocity at margin

$v_{\mathrm{i}}$ with respect to bedrock $\left(\mathrm{m} \mathrm{a}^{-1}\right)$

$1.1 \pm 0.2$

Surface slope $\alpha$

$1 \mathrm{~km}$ below to $10 \mathrm{~km}$ above thermistor line

$1 \mathrm{~km}$ below to $20 \mathrm{~km}$ above thermistor line

$1.3 \times 10^{-3}$

$1.1 \times 10^{-3}$

Ice thickness at Dragon Pad (m)

910

outer part of the Dragon (Lost Love and Chaos), the temperatures tend to be somewhere between these two extremes but more similar to the Unicorn sites. At intermediate depths, temperatures at Lost Love and Chaos indicate a warming trend relative to those at Dragon Pad, an effect that will be analyzed below in terms of internal heating. Considering both the complicated structure of the these temperature profiles and the complicated history of the ice stream as noted above, one expects all of the measured temperatures to be changing with time.

\section{Origin of the ice}

One of the most important factors in the analysis of the temperature data in the Dragon is the origin of the ice there. If the ice at a particular site in the Dragon came from a nearby site in the Unicorn like Dragon Pad, where the temperature is known, then the difference in temperatures at the two sites can be interpreted in terms of two processes which occur as Unicorn ice becomes incorporated into the Dragon, cooling from the surface and heating internally. Because the ice in the Unicorn near the ice stream has a component of velocity directed into the ice stream and because, as will be shown later, the Dragon is migrating into the Unicorn, it is safe to assume that the ice in the outermost part of the Dragon (such as at Lost Love and possibly at Chaos) originated on the Unicorn.

In contrast to this situation, there are two reasons indicating that the ice at the other sites (Remote, Intermediate and Pad) did not originate on the Unicorn. First, they have characteristically different temperatures at intermediate depths, as mentioned above. Secondly, because of the rapid acceleration of a parcel of ice from the Unicorn as it becomes part of the Dragon, its trajectory soon makes a small angle with respect to the outer edge of the Dragon. This means that the ice at Remote, Intermediate and Pad probably originated far enough upstream that it never had the temperatures presently characteristic of ice in the Unicorn and, because of this different origin, it probably also had a different history of surface cooling and internal heating. It is interesting that between Chaos and Remote a shallow, trench-like feature has been identified (Echelmeyer and others, 1994). This is in the boundary area between the two groups of sites showing the characteristically different temperature behavior and could be another indication of their different origin. Even within the group of sites consisting of Remote, Intermediate and Pad, the temperature contours of Figure 5 illustrate that the temperature behavior is 
complex. Analysis of the temperature profiles at these three sites seems difficult and is not attempted in this paper.

\section{MIGRATION VELOCITY OF THE ICE-STREAM MARGIN AND LATERAL SHEAR STRESS}

\section{A. Approach}

In this section, the temperatures at Lost Love and Chaos are analyzed under the assumption that the ice there originated from the Unicorn and initially had the same temperature profile as measured at Dragon Pad; the data from these three sites are singled out in Figure 7. As noted above, when the ice enters the Dragon from the Unicorn (or as the Dragon migrates into the Unicorn), it experiences two effects: cooling from the surface due to the new "surface" temperature $\left(-37.0^{\circ} \mathrm{C}\right.$ at a depth of $\left.30 \mathrm{~m}\right)$ imposed by the crevassing, and internal heating due to energy dissipated by ice deformation. These effects can be analyzed to give both the velocity of migration of the edge of the ice stream and the lateral shear stress acting across an approximately vertical plane parallel to the edge of the ice stream.

The analysis requires several approximations, which are discussed in more detail in the next section. The most important approximation requires that the Dragon and adjacent parts of the Unicorn do not and have not varied significantly upstream from the study site along the trajectories followed by the ice now at Lost Love and Chaos. More specifically, we assume that there is longitudinal homogeneity (no longitudinal temperature gradients) and that conditions have not changed with time in a reference system moving transversely with the edge of the ice stream. In this case, it is justified to analyze an element of ice at Lost Love or Chaos as if it and the edge of the ice stream had moved along a line perpendicular to the ice stream rather than along the actual trajectories. With the help of further approximations, the ice can be analyzed as a simple moving column in one spatial dimension.

Although the margin-migration velocity and the lateral shear stress are the desired results of the analysis, it is more

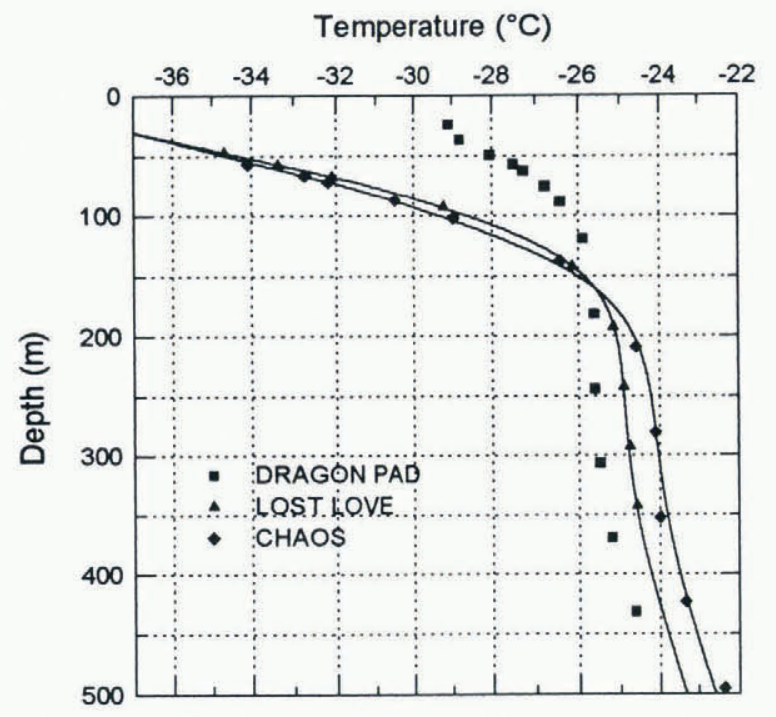

Fig. 7. The three temperature profiles analyzed (symbols) and the model fits (curves). The fits to the Lost Love data were made with both the immediate and delayed cooling models and with two slightly different sets of parameters; the fits are indistinguishable on this scale. convenient to begin by extracting two other quantities, more directly related to the data, from which the migration velocity and the shear stress can be easily calculated. The first quantity is the "residence time" $\Delta t$, which is the time that a column of ice has resided in the Dragon and therefore the time that it has undergone surface cooling and internal heating, at least in the approximation in which these two processes proceed simultaneously. The second quantity is the "internal heating rate", which is the rate of temperature change that the column would experience if it were isolated except for the internal heating by ice deformation. This is equal to the quotient $f / \rho c$ where $f$ is the rate of volumetric heat production by deformation of the ice and $\rho c$ is the volumetric heat capacity.

\section{B. Determination of residence time and internal heating rate}

An instructive approximate approach to the problem of determining the residence time and the internal heating rate for a column of ice now at Lost Love is as follows. Take the "effective surface" of the ice stream to be a horizontal plane at a depth of $30 \mathrm{~m}$, the approximate thickness of the crevassed layer. Assume that the column initially had the temperature profile measured at Dragon Pad, and that when it entered the Dragon, the temperature at the effective surface dropped to $-37.0^{\circ} \mathrm{C}$ and the internal heating rate jumped from zero to some constant value. At relatively shallow depths, cooling would dominate. One can then obtain an order-of-magnitude estimate of half a century for the residence time $\Delta t$, using the fact that the depth of cooling (seen in Figure 7 to be characteristically $80-100 \mathrm{~m}$ below the effective surface) increases roughly as $\sqrt{4 \kappa \Delta t}$ where $\kappa$ is the thermal diffusivity of ice. At intermediate depths $(>150 \mathrm{~m})$, internal heating would be dominant. The temperature increase between Dragon Pad and Lost Love is about the same at all intermediate depths (Fig. 7), roughly $0.8 \mathrm{~K}$. Division by $\Delta t$ gives an order-of-magnitude estimate of 1 or $2 \mathrm{~K}$ per century for the internal heating rate, which is approximately independent of depth.

A more accurate analysis uses a simplification of the heat-transport equation:

$$
\frac{1}{\rho c}\left(\frac{\partial}{\partial z}\left(K \frac{\partial T}{\partial z}\right)\right)-\dot{b}\left(1-\frac{z}{H}\right) \frac{\partial T}{\partial z}+\frac{f}{\rho c} \cong v_{\mathrm{i}} \frac{\partial T}{\partial y}+\frac{\partial T}{\partial t}
$$

where $T$ is the temperature and $t$ is time. The $(x, y, z)$ coordinate system is fixed relative to bedrock, with the $x$ axis oriented downstream, $y$ into the ice stream and $z$ vertically down. The origin is taken to be at Dragon Pad at the effective surface, $30 \mathrm{~m}$ below the true surface. $K$ is the thermal conductivity of ice and $\rho c$ is its volumetric heat capacity; they were taken to vary smoothly with temperature according to the parameterization given in Paterson (1994). $\dot{b}$ is the balance rate in ice-equivalent units, $H$ is the ice thickness, $f$ is the volumetric rate of internal heat production and $v_{\mathrm{i}}$ is the velocity component of the ice perpendicular to the edge (along the $y$ axis) measured with respect to bedrock.

In Equation (1) the first and second terms represent conduction and advection in the vertical direction, the latter with a linear vertical velocity distribution (or constant vertical strain rate). There are no corresponding terms in the longitudinal direction because of the assumed longitudinal homogeneity noted above. The third term is the internal 
heating rate, which is taken to be independent of depth because of the uniform temperature changes at intermediate depths noted above. Conduction in the transverse direction is omitted but transverse advection is included through the first term on the righthand side. $v_{\mathrm{i}}$ is assumed to be independent of depth, with the consequence that the two terms on the righthand side together represent the temperature change $\mathrm{D} T / \mathrm{D} t$ in a vertical column of ice as it enters the ice stream from Dragon Pad and proceeds to Lost Love or Chaos. As far as the column is concerned, only the vertical dimension occurs. The key approximations, which include Equation (1) itself, the parameterization of the terms in it and the application of the surface boundary condition, are discussed in section $\mathrm{V}$.

Equation (1) governs the dependence of temperature as a function of depth in a moving column, and it can be used to find the values of the residence time and internal heating rate which best fit the measured temperatures at Lost Love and Chaos, using the data from Dragon Pad as the initial condition of the column. The results are insensitive to initial temperatures at depths greater than we measured at Dragon Pad but we did include measurements made there by the California Institute of Technology at depths greater than $600 \mathrm{~m}$ (personal communication from H. Engelhardt, 1994). As the lower boundary condition, we arbitrarily held the temperature gradient constant at the bed; this choice has no appreciable effect on the results, because the depths of our measured temperatures in the Dragon are too shallow and the residence times are too short.

In the simplest model, one of "immediate surface cooling", an immediate drop in effective surface temperature from the measured value at Dragon Pad to $-37.0^{\circ} \mathrm{C}$ was imposed on the moving column. Trial values of the residence time $\Delta t$ (the integration time) and the internal heating rate $(f / \rho c)$ (taken to be constant), were chosen to calculate the temperature profile from Equation (1), and varied to give the best fit (in the least-squares sense) to the measured temperatures at Lost Love. Because temperatures were measured at many depths, and there are only two unknown parameters, both are well determined. The temperature data used are shown in Figure 7; those at the shallowest depths were not included because we could not remove the effects of drilling, possible seasonal changes or possible small temperature inhomogeneities associated with the small but finite spacing of the crevasses which determine the effective surface temperature. The resulting best values of residence time and internal heating rate are designated by the subscript 2 and are in Table 2; the residence time is from 1952 to the time of measurement in 1994, loosely referred to as "the present" in our discussion. The errors given in Table 2 are those resulting from uncertainty in temperature measurement and indicate how well the two parameters are determined by the data if the model is accurate.

If one were to apply the same approach to the Chaos data, the results would be different. This is suggested by Figure 7 , which indicates that internal heating has progressed significantly at Chaos relative to Lost Love (seen in the data at intermediate depths, $>150 \mathrm{~m}$ ) but a commensurate downward cooling (seen in the shallower data) has not. The latter suggests that the residence time of the ice at Chaos has been only slightly longer than that at Lost Love, so that the internal heating rate (averaged over its residence time) must have been larger than at Lost Love. Since the ice at Chaos has been in the Dragon somewhat longer than that
Table 2. Calculated internal heating rates $(f / \rho c)$ and corresponding time intervals $\Delta t$ for the immediate and delayed surface-cooling models, together with the errors arising from the errors in temperature measurement. Values for the second (more recent) interval $\Delta t_{2}$ are given for two different sets of parameters, as indicated. Details are in the text

\begin{tabular}{|c|c|c|c|}
\hline Surface-cooling model & $\begin{array}{l}\text { Internal heating rate } \\
\qquad \mathrm{K} \mathrm{a}^{-1}\end{array}$ & $\begin{array}{l}\text { Time interval } \\
\text { a }\end{array}$ & $\begin{array}{l}\text { Fit rmserror } \\
\qquad \mathrm{K}\end{array}$ \\
\hline \multicolumn{4}{|c|}{ Parameters $\quad \dot{b}=0.15 \mathrm{ma}^{-1}, \quad H=992 \mathrm{~m}$ : } \\
\hline $\operatorname{Immediate}(f / \rho c)_{1}$ & $=0.033 \pm 0.007$ & $\Delta t_{1}=22 \pm 6$ & 0.15 \\
\hline $\operatorname{Immediate}(f / \rho c)_{2}$ & $=0.0163 \pm 0.0014$ & $\Delta t_{2}=42.4 \pm 1.5$ & 0.04 \\
\hline $\operatorname{Delayed}(f / \rho c)_{2}$ & $=0.0139 \pm 0.0013$ & $\Delta t_{2}=52.5 \pm 1.5$ & 0.03 \\
\hline \multicolumn{4}{|c|}{ Parameters $\quad \dot{b}=0.09 \mathrm{~m} \mathrm{a}^{-1}, \quad H=910 \mathrm{~m}:$} \\
\hline $\operatorname{Delayed}(f / \rho c)_{2}$ & $=0.0125 \pm 0.0013$ & $\Delta t_{2}=56.0 \pm 1.5$ & 0.03 \\
\hline
\end{tabular}

at Lost Love, an internal heating rate that is decreasing in time is suggested.

As the simplest test of this tentative conclusion, we defined an earlier interval $\Delta t_{1}$ (coming just before $\Delta t_{2}$ ) during which the ice now at Chaos had entered the Dragon but that now at Lost Love had not. This would be the interval before 1952. We allowed for a different internal heating rate $(f / \rho c)_{1}$ during this earlier interval. For the more recent interval $\Delta t_{2}$ (from 1952 to 1994), we took the internal heating rate to be the same as for Lost Love, $(f / \rho c)_{2}$ from Table 2. $\Delta t_{1}$ and $(f / \rho c)_{1}$ were then determined by a least-squares fit to the Chaos data, again by integrating Equation (1) using the Dragon Pad data as the initial condition. The results are in Table 2. $\Delta t_{1}$ began in 1930; this is the year that the ice now at Chaos entered the Dragon according to this model. The internal heating rate during this earlier period was about twice as large as it was after 1952. However, it is most realistic to think of these rates as averages over their respective time intervals; it is unlikely that there was an abrupt change in that year.

The resulting best fits to the Lost Love and Chaos data are shown by the curves in Figure 7 . The rms error between the fitted temperature curves and the data are in Table 2 and are comparable to the measurement errors. The values of accumulation rate $\dot{b}$ and ice thickness $H$ used in the fits are given in Table 2; these choices and their consequences are discussed in the next section.

Two questionable aspects of this approach are that the column experienced an internal heating rate that was independent of time (but different during the separate intervals $\Delta t_{1}$ and $\Delta t_{2}$ in the case of the column now at Chaos) and that the onset of surface cooling was immediate. We first consider the internal heating. One can see that heating has in fact already begun at Dragon Pad (compare with Stage or Out B in Figure 4), but this is of no consequence because we take the measured temperature there as the initial condition of the calculation. The variation of the measured surface strain rate (approximately half of the velocity derivative in Figure 3) with transverse position, and therefore with time as far as the moving column is concerned, may be indicative of variation in the internal heating rate as well. In the model we take it to be constant at the average value. However, this probably introduces little error into the 
results because, to a good approximation, it is the average value of the internal heating rate that influences the temperature change.

The situation with the surface cooling is not as clear. The discussion of the crevasse temperatures in the previous section indicates that the effective surface temperature of $-37.0^{\circ} \mathrm{C}$ at $30 \mathrm{~m}$ is not reached just beyond Dragon Pad, as assumed in our model. Moreover, the discussion of the structure of the chaotic zone in connection with Figure 3 indicates that chaotic crevassing, a sufficient but perhaps not necessary condition for the $-37.0^{\circ} \mathrm{C}$ temperature, is not developed until some distance beyond Dragon Pad. It therefore seems more realistic to use a "delayed surface cooling" model in which the $-37.0^{\circ} \mathrm{C}$ temperature occurs as a step one-quarter of the distance from Dragon Pad to Lost Love. The position of this step is our estimate of where the effective surface temperature reaches its average value between Dragon Pad and Lost Love. To apply this boundary condition, the drop in surface temperature was taken to occur at a quarter of the residence time, as would be the case for a constant inward component of velocity of the column relative to the margin.

The essential features of this delayed surface cooling model are summarized in Figure 8. The results from fitting the Lost Love data are given in Table 2; there are in fact two sets of results for two different fits, one for each of two different sets of values for the parameters $\dot{b}$ and $H$, as indicated in the table and discussed below. The best fit using the first set of parameters and the immediate cooling model is the curve shown in Figure 7, but the fits using the different parameter sets and cooling models are all very good and cannot by themselves single out one set or model as being superior. The delayed cooling model was not applied to the Chaos data because of complications discussed below.

\section{Migration velocity and lateral shear stress}

The average outward component of the migration velocity of the ice stream, $v_{\mathrm{m}}$, during the interval $\Delta t_{2}$ can be calculated from $\Delta t_{2}$, the distance between Dragon Pad and Lost Love, $d_{\mathrm{DP} \rightarrow \mathrm{LL}}$, and the component of the ice velocity (measured with respect to bedrock) directed inward into the ice stream from the Unicorn, $v_{\mathrm{i}}$. If $v_{\mathrm{i}}$ were zero, the result would be simply $v_{\mathrm{m}}=\frac{d_{\mathrm{DP}-1 \mathrm{~L}}}{\Delta t_{2}}$. However, because $v_{\mathrm{i}}$ is not zero (Table 1), the residence time is determined by the "relative velocity", $v_{\mathrm{r}}$, which is the velocity of the column relative to the migrating edge of the ice stream:

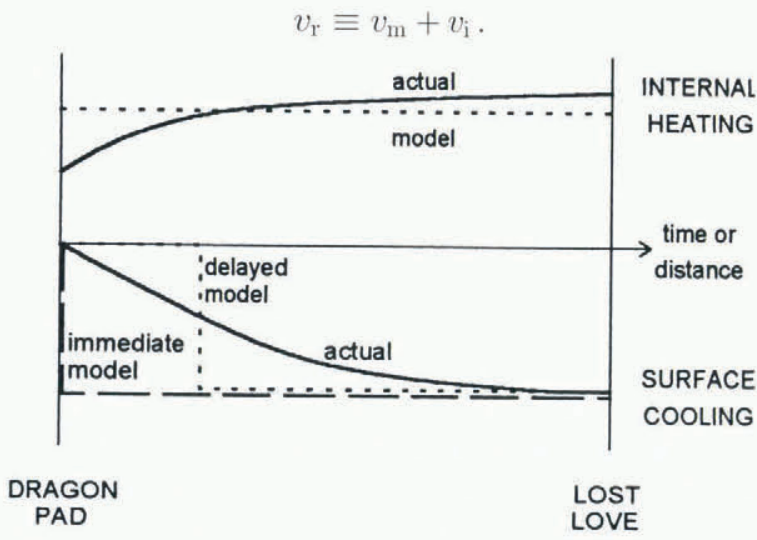

Fig. 8. Schematic sketch of the internal heating rate and of the surface cooling for the two model scenarios. The surface cooling is the temperature at $30 \mathrm{~m}$ depth.
The migration velocity is determined by

$$
\left(v_{\mathrm{m}}+v_{\mathrm{i}}\right) \Delta t_{2}=d_{\mathrm{DP} \rightarrow \mathrm{LL}} .
$$

Taking $v_{\mathrm{i}}, d_{\mathrm{DP} \rightarrow \mathrm{LL}}$ and $\Delta t_{2}$ from Tables 1 and 2 , we obtain the model-dependent value of $v_{\mathrm{m}}$ during the interval $\Delta t_{2}$. The corresponding value for the earlier interval $\Delta t_{1}$ is obtained by using the distance between Lost Love and Chaos from Table 1 . The results are in Table 3 . Note that $v_{\mathrm{m}} \gg v_{\mathrm{i}}$.

The lateral shear stress, $\tau_{x y}$, can be estimated from the Lost Love data for the more recent interval $\Delta t_{2}$ using

$$
f \cong 2 \dot{e}_{x y} \tau_{x y}
$$

where $\dot{e}_{x y}$ is the lateral shear strain rate (Table 1), which is assumed to be the only significant component of the strainrate tensor. Both $\tau_{x y}$ and $\dot{e}_{x y}$ were assumed to be independent of depth and time, as discussed in the next section. For $\dot{e}_{x y}$, we used the average value between Dragon Pad and Lost Love (Table 1 and Fig. 3). The resulting values of lateral shear stress for the models of immediate and delayed surface cooling are in Table 3 .

A more complex procedure was needed to find $\tau_{x y}$ for the earlier interval $\Delta t_{1}$, because the flow regime then, unlike today's, is unknown. We used a flow-law approach, assuming that $\dot{e}_{x y}$ is proportional to $\tau_{x y}^{3}$, with the proportionality constant determined by the results obtained for these quantities during $\Delta t_{2}$. Under these conditions it is straightforward to show from Equation (4) that

$$
\left(\tau_{x y}\right)_{1}=\left(\frac{f_{1}}{f_{2}}\right)^{\frac{1}{4}}\left(\tau_{x y}\right)_{2}
$$

in which the subscripts denote the two time intervals. This result is also given in Table 3 . The dates of the intervals in Table 3 correspond to the values of $\Delta t_{1}$ and $\Delta t_{2}$ in Table 2 . In both tables the uncertainties are those estimated from measurement errors alone; the effects of shortcomings in the models are not included.

\section{UNCERTAINTIES}

The values of migration velocity and shear stress in Table 3 are affected by a variety of factors. The first is the effect of errors in the temperature measurements, which is relatively sinall (Table 3) and needs no further discussion. The others

\begin{tabular}{|c|c|c|c|c|}
\hline $\begin{array}{l}\text { Surface-cooling } \\
\text { model }\end{array}$ & Time interval & $\begin{array}{l}\text { Relative } \\
\text { velocity } v_{\mathrm{r}} \\
\mathrm{ma}^{-1}\end{array}$ & $\begin{array}{l}\text { Migration } \\
\text { velocity } v_{\mathrm{m}} \\
\mathrm{ma}^{-1}\end{array}$ & $\begin{array}{c}\text { Shear stress } \\
\qquad \tau_{x y} \\
10^{5} \mathrm{~Pa}\end{array}$ \\
\hline & Parameters $\dot{b}=$ & $0.15 \mathrm{ma}^{-1}$ & $H=992 \mathrm{~m}:$ & \\
\hline Immediate & $1930-52$ & $28 \pm 8$ & $27 \pm 8$ & $3.1 \pm 0.7$ \\
\hline Immediate & $1952-94$ & $11.1 \pm 0.4$ & $10.0 \pm 0.4$ & $2.6 \pm 0.3$ \\
\hline \multirow[t]{2}{*}{ Delayed } & $1941-94$ & $8.5 \pm 0.4$ & $7.4 \pm 0.4$ & $2.2 \pm 0.3$ \\
\hline & Parameters $\dot{b}$ & $0.09 \mathrm{~m} \mathrm{a}^{-1}$ & $H=910 \mathrm{~m}:$ & \\
\hline Delayed & 193894 & $8.4 \pm 0.4$ & $7.3 \pm 0.4$ & $2.0 \pm 0.3$ \\
\hline
\end{tabular}
are discussed under the following three headings.

Table 3. Average migration velocity and lateral shear stress 


\section{A. The heat transport equation - transverse con- duction, vertical advection, thermal properties and ice velocity}

The omission of the conduction term in the transverse direction from Equation (1) can be justified on dimensional grounds. The characteristic conduction length in the transverse direction is $\kappa / v_{\mathrm{r}}$, where $\kappa$ is the thermal diffusivity. This is about $4 \mathrm{~m}$, which means that temperatures within a few meters of the edge of the ice stream would be influenced by transverse conduction but not at the much greater distances characteristic of Lost Love or Chaos.

The simple parameterization of the vertical advection term in Equation (1) also needs to be justified. One approach is to compare the characteristic depths to which heat is transported by conduction and advection during the time $\Delta t$, which we take to be $\sqrt{4 \kappa \Delta t}$ and $\dot{b} \Delta t$, respectively. At both Lost Love and Chaos, the conduction depth exceeds the advection depth by an order of magnitude, which suggests that the advection term, and therefore the values of the parameters $\dot{b}$ and $H$ in it, are not critical. This is borne out by sensitivity tests using the delayed cooling model in the Lost Love analysis. Analyses which we carried out using preliminary values of $\dot{b}=0.15 \mathrm{~m} \mathrm{a}^{-1}$ and $H=$ $990 \mathrm{~m}$ are useful in these tests, when compared with analyses using the more realistic values of $0.09 \mathrm{~m} \mathrm{a}^{-1}$ (measured by Alley and Bentley (1988) at a site $15 \mathrm{~km}$ to the north) and $910 \mathrm{~m}$ (Table 1). Decreasing $\dot{b}$ from 0.15 to $0.09 \mathrm{ma}^{-1}$ decreases $\tau_{x y}$ by about $7 \%$, and decreasing $H$ from 990 to $910 \mathrm{~m}$, decreases $\tau_{x y}$ by about $4 \%$. The net result of varying these parameters can be seen in Tables 2 and 3 . We used the preliminary values of $\dot{b}$ and $H$ and only the immediate cooling model in the Chaos analysis, because we judged more effort to be unjustified given the large uncertainty in the history of the Chaos column, discussed below.

Our choice of thermal properties also needs to be justified. We used a value of thermal conductivity $K$ characteristic of pure ice. The accuracy of this approximation depends upon how closely the density below the $30 \mathrm{~m}$ reference surface approaches that of solid ice. Judging from measurements made near the center of the ice stream (Alley and Bentley, 1988), this occurs at about $15 \mathrm{~m}$ below our effective surface, but the depth is probably less between Dragon Pad and Lost Love because the densification rate is likely higher near the edge of the ice stream due to its strain-rate dependence. We therefore judge that this is not a major source of error. Even less important is the possible error in the volumetric heat capacity $\rho c$, for which we used the weak but correct temperature dependence in the solution of Equation (1), and the single value at $-28^{\circ} \mathrm{C}$ for converting the resulting best values of $f / \rho c$ to $f$.

Finally, the use of the moving-column model requires that the horizontal velocity of the ice in the transverse direction, $v_{\mathrm{i}}$, is independent of depth. This turns out to be of little consequence because $v_{\mathrm{i}}$ is small compared with the migration velocity $v_{\mathrm{m}}$.

\section{B. Longitudinal and temporal changes in the config- uration of the ice stream}

Two effects noted in the previous section are more serious than those just considered. The first is the assumption of longitudinal homogeneity, which leads to the omission of the longitudinal conduction and advection terms in Equa- tion (1), and the second is the assumption of time independence in the configuration of the ice stream. These effects could cause uncertainties in the surface cooling and internal heating histories of the Lost Love and Chaos columns.

To treat the possible effects of longitudinal variations in the ice stream, we begin by assuming that they are small and that there is no temporal variation in the configuration of the ice stream except for uniform translation. Then we determine the "entry points", which are the points upstream of Lost Love and Chaos where the ice columns now at these sites entered the Dragon. Finally, we consider whether it is reasonable that the properties of the ice stream could be unchanging on such longitudinal spatial scales. The version of the model with immediate surface cooling is used for simplicity.

If the longitudinal (downstream) velocity component, $v_{x}$, is approximated by

$$
\begin{aligned}
v_{x} & =\frac{\partial v_{x}}{\partial y^{\prime}} y^{\prime} \\
& \cong 2 \dot{e}_{x y} y^{\prime}
\end{aligned}
$$

in which $y^{\prime}$ is the transverse coordinate measured into the ice stream from its moving edge and $\dot{e}_{x y}$ is taken to be constant near $y^{\prime}=0$, it follows that the rate of change of the longitudinal position $X$ of a column of ice is given by

$$
\frac{\mathrm{d} X}{\mathrm{~d} t}=2 \dot{e}_{x y} Y^{\prime}
$$

where $Y^{\prime}$ is the distance of the column from the edge of the ice stream. Also

$$
\frac{\mathrm{d} Y^{\prime}}{\mathrm{d} t}=v_{\mathrm{r}}
$$

where $v_{\mathrm{r}}$ is the transverse velocity of a column measured with respect to the moving edge of the ice stream (Equation (2)). Integration of Equations (7) and (8) gives

$$
X(t)-X(t=0)=\dot{e}_{x y} v_{\mathrm{r}} t^{2}
$$

in which the column entered the Dragon at $t=0$. The lefthand side is the distance upstream to the entry point. The approximations leading to Equation (9) are consistent with those made in the immediate cooling model when it was applied to the Lost Love temperatures, with $t$ corresponding to the residence time $\Delta t_{2}$.

Using Equation (9) and the necessary information from Tables 1, 2 and 3, the entry point of the column now at Lost Love is found to be about $1.0 \mathrm{~km}$ upstream. The same approach, but allowing for the longer and more complicated modelled history, gives roughly $4 \mathrm{~km}$ upstream for the Chaos entry point. The uncertain history of the strain rate produces some uncertainty in these values, particularly in the case of the Chaos column. Over a distance of $1 \mathrm{~km}$ upstream, casual observation indicates no change in the ice stream, so the requirement of lateral homogeneity for Lost Love is probably well satisfied. The situation is not quite as good for Chaos, because on a scale of $10 \mathrm{~km}$, at least, the Dragon does change, becoming less crevassed upstream.

We still have to consider the effects of possible time dependence in the configuration of the ice stream. For example, it was noted above that the head of the ice stream is migrating upstream. If the Dragon has also been doing so, the Chaos column might have had an actual entry point near what was then the upper end of the Dragon (Fig. 1) and would have encountered different conditions. In this scenario, it would be particularly important to take into ac- 
count the delayed commencement of surface cooling, because it takes time for crevasses to develop, not only as the margin migrates laterally but as it migrates upstream. This alone could explain the limited depth to which cooling seems to have penetrated at Chaos, and therefore why the internal heating rates (Table 2) and migration velocities (Table 3) for the intervals $\Delta t_{1}$ and $\Delta t_{2}$ were so different.

Considering these two problems, which together cause uncertainty in the histories of the ice columns, it seems wisest to view the results for the earlier interval $\Delta t_{1}$ with suspicion. At best, they are less accurate than those for the more recent interval; at worst, the errors are large because of the considerable uncertainty in the history of the Chaos column. This is the same problem (although less severe) that prevented us from attempting an analysis of the temperatures from Pad, Intermediate and Remote. The results for the more recent interval are considerably less sensitive to these effects. Nevertheless, even in this case we judge that the basic problem, the uncertain surface cooling and strain history of the Lost Love column due to longitudinal and temporal changes in the configuration of the ice stream, may be significant. A related possibility, that the migration velocity may have varied in time, seems less important if our migration velocity is considered an average over the time interval $\Delta t_{2}$.

\section{Internal heating rate and the upper boundary condition}

Regardless of the problem of longitudinal and temporal changes in the configuration of the ice stream, we need to consider in more detail our treatment of internal heating and surface cooling used in the analysis of the Lost Love data. Considering first the internal heating rate, we recall that it was taken to be independent of depth. The high quality of the fits indicates that this is an excellent assumption. This is not surprising at intermediate depths, at least, because of the uniformity of the temperature differences between the Dragon Pad and Lost Love profiles (Fig. 7). The situation is less obvious and probably not so well determined at shallow depths because of the complications of surface cooling, although the fits here are also excellent.

Considering the surface boundary condition, Table 3 shows that the estimated values of migration velocity and lateral shear stress are sensitive to the surface-cooling model. The differences between the immediate and delayed cooling models are typically $20 \%$ applied to the recent time interval $\Delta t_{2}$. The values obtained with the delayed model are more realistic but uncertainties remain: the use of a delayed step rather than a more realistic function (Fig. 8), uncertainty in the timing of the step and the related effect of a time-dependent migration velocity. We judge that the uncertainty in the cooling model contributes an error of about $15 \%$ to migration velocity and lateral shear stress; this is one of the main contributions to the net error as discussed below.

\section{Independence of lateral shear strain rate on time and depth}

Because of Equation (4), the lateral shear stress $\tau_{x y}$ depends upon both the internal heating rate and the shear strain rate. Since our best value for the internal heating rate is an average over the time interval from about 1938 to 1994, our value for the lateral shear stress should be viewed the same way. However, this requires the strain rate experienced by the moving column to have been similar to what one would compute from the present strain rate with a constant migration velocity. The uncertainty in this assumption is a major consideration in the estimation of net errors, as noted above.

A parallel question is the depth dependence of the strain rate, previously considered theoretically by Echelmeyer and others (1994), Raymond (1996) and Jacobson and Raymond (1998). The strong cooling which we observed in the shallow ice suggests that it is relatively stiff, and thus that the shear strain rate, and therefore the velocity, would increase with depth. Then the independence of the internal heating rate on depth (with the limitations discussed above) would imply by Equation (4) a decreasing shear stress with depth. One might think that the value of the shear stress in Table 3 is best interpreted as a near-surface value, because it is estimated using the measured surface strain rate. On the other hand, the internal heating rate which determines it is best known at intermediate depths. It is probably best to consider our value to be representative of the top third of the ice stream, which is the maximum depth of the temperature measurements at Lost Love.

\section{E. Best values and net errors}

The analysis of the Lost Love data, using the delayed cooling model and the best parameter values, can be summarized as follows. From about 1938 to 1994, the lateral shear stress in the upper third of the ice-stream thickness averaged about $2.0 \times 10^{5} \mathrm{~Pa}$ and the edge of the ice-stream migrated outward into the ice sheet at an average speed of about $7.3 \mathrm{~m} \mathrm{a}^{-1}$. Although there are many uncertainties, we believe the net error is dominated by two primary contributions, the uncertainty in the appropriate surface cooling model $(15 \%)$ and a comparable contribution from the uncertainty in the history of the moving column. Treating these contributions as independent, we obtain an estimate of about $20 \%$ for the net uncertainty in the shear stress and the migration velocity. The latter seems less sensitive to strain rate and its uncertainty may in fact be somewhat less.

The results from the Chaos analysis are much more sensitive to these effects and are not considered reliable, although at face value they suggest that the migration velocity was higher some decades earlier.

\section{DISCUSSION AND SUMMARY}

\section{A. Force balance}

Our analysis indicates that the lateral shear stress in the upper third of the ice stream averaged $2.0 \times 10^{5} \mathrm{~Pa}$ over the last half century. This permits us to address one of the key questions discussed in the first section: the extent to which the downstream component of the weight of the ice stream is supported by its sides. In this discussion it is convenient to use the idea of the "driving stress" $\bar{\tau}_{\mathrm{d}}$ defined by

$$
\bar{\tau}_{\mathrm{d}} \equiv \rho g H \sin \alpha
$$

where $\rho$ is the density of the ice, $g$ is the gravitational acceleration, and $H$ and $\alpha$ are the average values of the ice thickness and surface slope. If longitudinal forces are negligible, force balance is expressed in the form

$$
\bar{\tau}_{\mathrm{d}}=\bar{\tau}_{\mathrm{b}}+\frac{2 H_{\mathrm{m}}}{W} \bar{\tau}_{x y}
$$

in which $H_{\mathrm{m}}$ is the average thickness at the margins, $W$ is 
the width of the ice stream, $\bar{\tau}_{\mathrm{b}}$ is the average basal shear stress and $\bar{\tau}_{x y}$ is the lateral shear stress averaged over depth along each margin. The idea is to investigate how the driving stress (the lefthand side of Equation (11)) is partitioned between basal drag and side drag.

To estimate the driving stress, we used our measured value $\alpha=1.3 \times 10^{-3}$ for surface slope (Table 1 ) and the value $H=1050 \mathrm{~m}$ for the average ice thickness. There is potentially a large uncertainty in $\alpha$, because $\alpha$ is small and the surface of the ice stream is irregular, but our value agrees with the value obtained by Echelmeyer and others (1994) from the map by Retzlaff and others (1993). This value is half that quoted by Alley and others (1987). The resulting driving stress $\bar{\tau}_{\mathrm{d}}$ is $0.12 \times 10^{5} \mathrm{~Pa}$.

To estimate the side-drag term, $\frac{2 H_{w}}{W} \tau_{x y}$, we use a value of $0.9 / 31$ for $H_{\mathrm{m}} / W$, which is consistent with the measured thickness near the margin (Table 1), and our value of $2.0 \times 10^{5} \mathrm{~Pa}$ to approximate the average lateral shear stress $\bar{\tau}_{x y}$. The result is $0.12 \times 10^{5} \mathrm{~Pa}$. This is the same as the driving stress, which at face value means that the average basal shear stress is essentially zero; all of the driving stress is taken up by the sides of the ice stream. However, one needs to keep the uncertainties in mind: the $20 \%$ which we assigned to the lateral shear stress, a comparable uncertainty in the surface slope, the fact that we have determined the lateral shear stress only in the upper third of the ice thickness at only one site and on only one side, and the assumption of negligible longitudinal forces. Nevertheless, it is clear that side drag is important and that it seems to support the most of the driving stress, in agreement with all other estimates.

Our estimate of the lateral shear stress is $10 \%$ lower than that of Jackson and Kamb (1997), which is perhaps fortuitously good agreement given the difficulty and uncertainty inherent in any method of stress measurement. Our lateral shear stress and side drag are higher than those estimated by Echelmeyer and others (1994), but perhaps not surprisingly so when one considers our uncertainties and the fact that their estimates were made on the basis of surface measurements alone and the assumption of constant temperature.

\section{B. Migration of the edge of the ice stream}

Our analysis indicates that the margin migrated outward at an average rate of about $7 \mathrm{~m} \mathrm{a}^{-1}$ between about 1938 and 1994. This is in reasonable agreement with a recent estimate by Hamilton and others (1998) based on crevasse shapes. A century or two earlier, the margin was moving more rapidly in the other direction (Clarke and Bentley, 1995). From a theoretical point of view, there is reason to doubt whether a margin could ever be stationary, unless there is an exact compensation by ice inflow or some compensating factors at the bed (Jacobson and Raymond, 1998).

\section{ACKNOWLEDGEMENTS}

The drilling was done with the California Institute of Technology hot-water rig and we are indebted to B. Kamb, H. Engelhardt and their field crew for its success and for their enthusiasm. Because of the unusually difficult field conditions, we also wish to thank people from several institutions who worked in the Dragon: J. Miller, A. Taylor, B. Montgomery, B. McCormick, K. Petersen, K.-N. Swenson, S.
Schmidt, L. Allison and several others. J. Gorda prepared the thermistor cables and R. Brandt helped set up the numerical calculations. We are grateful for the useful comments of H. P. Jacobson, C. F. Raymond and an anonymous referee. The financial support was from the U.S. National Science Foundation under grant DPP-9117911.

\section{REFERENCES}

Alley, R. B. and I. M. Whillans. 1991. Changes in the West Antarctic ice sheet. Science, 254 (5034), 959-963.

Alley, R. B., D. D. Blankenship, C. R. Bentley and S.T. Rooney. 1987. Till beneath Ice Stream B. 3. Till deformation: evidence and implications. J. Geophys. Res., 92 (B9), 8921-8929.

Alley, R. B. and C. R. Bentley. 1988. Ice-core analysis on the Siple Coast of West Antarctica. Ann. Glaciol., 11, 1-7.

Bentley, C. R. 1987. Antarctic ice streams: a review. J. Geophys. Res., 92 (B9), 8843- 8858.

Bindschadler, R. A. and P. L. Vornberger. 1990. AVHRR imagery reveals Antarctic ice dynamics. EOS, 71 (23), 741-742

Bindschadler, R. and P. Vornberger. 1998. Changes in the West Antarctic ice sheet since 1963 from declassified satellite photography. Science, 279 (5351), 689-692.

Bindschadler, R. A., S. N. Stephenson, D. R. MacAyeal and S. Shabtaie. 1987. Ice dynamics at the mouth of Ice Stream B, Antarctica. f. Geophys. Res., 92(B9), 8885-8894.

Clarke, T. S. and C. R. Bentley. 1995. Evidence for a recently abandoned ice stream shear margin. [Abstract.] EOS, 76 (46), Fall Meeting Supplement, F194.

Echelmeyer, K. A., W. D. Harrison, C. Larsen and J. E. Mitchell. 1994. The role of the margins in the dynamics of an active ice stream. F. Glaciol. $40(136), 527-538$.

Engelhardt, H. and B. Kamb. 1994. Vertical temperature profile of Ice Stream B. Antarct. 7. U.S., 28 (5), Review 1993, 63-66.

Hamilton, G. S., I. M. Whillans and P.J. Morgan. 1998. First point measurements of ice-sheet thickness change in Antarctica. Ann. Glaciol., 27, $125-129$.

Harrison, W. and K. Echelmeyer. 1994. Temperature measurements in the margin of Ice Stream B, 1993-1994. Antarct. J. U.S., 29 (5), Review 1994, $60-61$.

Hughes, T. 1975. The West Antarctic ice sheet: instability, disintegration, and initiation of ice ages. Rev. Geophys. Space Phys., 13(4), $502-526$.

Humphrey, N. and K. Echelmeyer. 1990. Hot-water drilling and bore-hole closure in cold ice. J. Glaciol., 36 124), 287-298.

Jackson, M. 1991. Repeat aerial photogrammetry of Ice Stream B, West Antarctica. (M.Sc. thesis, Ohio State University, Columbus.)

Jackson, M. and B. Kamb. 1997. The marginal shear stress of Ice Stream B, West Antarctica. 7. Glaciol., 43 (145), 415-426.

Jacobel, R.W., T. A. Scambos, C. F. Raymond and A. M. Gades. 1996. Changes in the configuration of ice stream flow from the West Antarctic ice sheet. f. Geophys. Res., 101 (B3), $5499-5504$.

Jacobson, H. P. and C. F. Raymond. 1998. Location of ice stream margins, thermal effects. 7. Geophys. Res., 103 (B6), 12,111-12,122.

Kamb, B. 1991. Rheological nonlinearity and flow instability in the deforming bed mechanism of ice stream motion. f. Geophys. Res., 96(B10), $16,585-16,595$.

Paterson, W.S.B. 1994. The physics of glaciers. Third edition. Oxford, etc., Pergamon Press.

Raymond, C. 1996. Shear margins in glaciers and ice sheets. 7. Glaciol, $42140,90-102$

Retzlaff, R., N. Lord and C.R. Bentley. 1993. Airborne-radar studies: Ice Streams A, B and C, West Antarctica. 7. Glaciol., 39 133), 495-506.

Shabtaie, S. and C. R. Bentley. 1986. Ice streams and grounding zones of West Antarctica and the Ross Ice Shelf. (Abstract.) Ann. Glaciol., 8, 199200.

Vornberger, P. L. and I. M. Whillans. 1986. Surface features of Ice Stream B, Marie Byrd Land, West Antarctica. Ann. Glaciol., 8, 168-170.

Vornberger, P. L. and I. M. Whillans. 1990. Crevasse deformation and examples from Ice Stream B, Antarctica. 7. Glaciol., 36 (122), 3-10.

Whillans, I. M. and C. J. van der Veen. 1993. New and improved determinations of velocity of Ice Streams B and C, West Antarctica. 7. Glaciol., 39 (133), 483-490.

Whillans, I. M. and C. J. van der Veen. 1997. The role of lateral drag in the dynamics of Ice Stream B, Antarctica. J. Glaciol., 43(144), 231-237. 